\title{
Use of social network analysis to examine preferential co-occurrences in Atlantic Sturgeon Acipenser oxyrinchus oxyrinchus Mitchill, 1815
}

\author{
Jessie Lilly ${ }^{{ }^{*}} \mathbb{0}$, Montana F. McLean ${ }^{1}$, Michael J. Dadswell1 ${ }^{1}$ Isaac Wirgin², Perry Comolli ${ }^{1}$ \\ and Michael J. W. Stokesbury'
}

\begin{abstract}
Background: Application of Social Network Analysis (SNA) to acoustic telemetry is a useful approach to examine social behavior in fish. Atlantic Sturgeon (Acipenser oxyrinchus oxyrinchus) are ancient, long-lived anadromous finfish. Although Atlantic Sturgeon have been the subject of numerous telemetry studies, none have used SNA to analyze their co-occurrence behavior. During 2010-2014 Atlantic Sturgeon $(n=103)$ that were later genetically identified as being from the Saint John River, Canada and the Kennebec River, US were captured by otter trawl and brush weir in Minas Basin, Bay of Fundy, Canada, and acoustically tagged. Using data from moored acoustic receivers within foraging habitat in Minas Basin, we tested if Atlantic Sturgeon formed social associations that were random or structured during 2012 to 2014; and whether these co-occurrences consisted of individuals from the same river of origin or capture date.
\end{abstract}

Results: Irrespective of genetic origin and initial capture date, Atlantic Sturgeon formed co-occurrences in Minas Basin that were significantly different than would be observed by chance during 2012 and very close to significant during 2013. Analysis demonstrated that some Atlantic Sturgeon preferentially co-occur within their primary feeding habitat.

Conclusions: The current threats to Atlantic Sturgeon aggregations within the Bay of Fundy, Nova Scotia, include bycatch in fisheries throughout their coastal migration routes and more recently the development of tidal turbines along their migratory corridor to their summer aggregation site. It is important to determine if Atlantic Sturgeon form aggregations with conspecifics from the same population to inform management decisions regarding threats to groups of individuals. This study indicated that Atlantic Sturgeon may form preferential co-occurrences within their feeding aggregation and co-occurrences that were identified were not dependent upon population of origin or initial capture date.

Keywords: Acipenser oxyrinchus oxyrinchus, Social network analysis, Minas Basin, Migration, Acoustic telemetry

*Correspondence: jessielilly@acadiau.ca

${ }^{1}$ Department of Biology, Acadia University, 33 Westwood Avenue, Wolfville, NS B4P 2R6, Canada

Full list of author information is available at the end of the article

\begin{abstract}
Background
Forming aggregations or groups with members of the same species is common within the animal kingdom [1]. Aggregations form when individuals from the same species utilize critical habitat including feeding, spawning and overwintering sites [2,3]. Co-occurrence behavior is highly dependent on the niche utilized by a species, and individual behavioral preferences [4]. Within
\end{abstract}

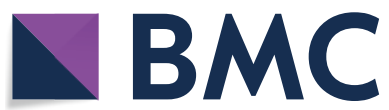

(c) The Author(s) 2020. This article is licensed under a Creative Commons Attribution 4.0 International License, which permits use, sharing, adaptation, distribution and reproduction in any medium or format, as long as you give appropriate credit to the original author(s) and the source, provide a link to the Creative Commons licence, and indicate if changes were made. The images or other third party material in this article are included in the article's Creative Commons licence, unless indicated otherwise in a credit line to the material. If material is not included in the article's Creative Commons licence and your intended use is not permitted by statutory regulation or exceeds the permitted use, you will need to obtain permission directly from the copyright holder. To view a copy of this licence, visit http://creativeco mmons.org/licenses/by/4.0/. The Creative Commons Public Domain Dedication waiver (http://creativecommons.org/publicdomain/ zero/1.0/) applies to the data made available in this article, unless otherwise stated in a credit line to the data. 
aggregations individuals can display preferential cooccurrences with specific individuals [5]. Preferential co-occurrences describe two individuals associating in a group more often than would be observed by chance [6]; these are categorized as representing social groups [5]. When individuals are passively sharing time and space and do not display a preference for whom they associate with then this is referred to as an aggregation [5].

Prior to the last decade, research concerning the formation of complex social groups has been limited to studies on terrestrial and marine mammals [7-9]. Excluding studies on collective behavior and schooling, fishes' ability for complex social behavior has received little attention [10]. Most studies have been conducted with shoaling species in a controlled laboratory or field setting [11-14], where the researcher can actively observe intraspecific interactions leading to a need to better understand associative behavior in large free-ranging fishes [15].

Social Network Analysis (SNA) is a primary method used to analyze the temporal and spatial patterns within animal populations [16]. SNA theory assumes that two individuals co-occur if they are within close enough temporal and spatial proximity to interact or associate [17]. SNA requires the time-stamped observations of interactions between individuals, and thus has traditionally been applied in observational studies [17-20]. Although interactions are difficult to define, the development of acoustic telemetry has enabled researchers to utilize SNA to estimate the strength and characteristics of interindividual co-occurrence between fishes [21, 22]. Acoustic telemetry involves the use of individuals that are equipped with uniquely coded acoustic transmitters coupled with acoustic receiving devices that are strategically placed enabling researchers to follow organisms across space and time [23, 24]. Co-occurrence strength can be determined based upon the frequency of co-occurrences at acoustic receivers [10]. For species that utilize small home ranges in regions that are densely populated with receivers, researchers can more accurately define social groups [6]. However, for large free-ranging fishes that occupy a diverse range of habitats with varying receiver coverage it is difficult to determine the degree of sociality expressed between organisms [15]. In free-ranging species SNA can be used to identify trends in aggregation behavior based on spatio-temporal co-occurrences between individuals $[6,10,25]$.

In this study SNA was used to identify patterns in cooccurrences in a large free-ranging chondrostean, the Atlantic Sturgeon (Acipenser oxyrinchus oxyrinchus Mitchill, 1815). Atlantic Sturgeon are an ancient, longlived (+60 years) anadromous species with a spawning range extending from the Gulf of St. Lawrence, Quebec,
Canada, to the St. John River, Florida, US [26]. In Canada, management recognizes two Designatable Units (DU) of Atlantic Sturgeon. One DU originates from the Saint John River (SJR), New Brunswick, and the other from the Saint Lawrence River, Quebec. In the US, five Distinct Population Segments (DPS) were listed under the Endangered Species Act (ESA) in 2012. These include the Carolina, Chesapeake, New York Bight, and South Atlantic DPS which are listed as endangered and the Gulf of Maine DPS which is listed as threatened [27, 28].

Fisheries' closures and habitat restoration have led to encouraging results including slight increases in the abundance of some populations [29]. Recovery of sturgeon is slow, however, primarily due to life-history traits like late age of maturity that results in delayed recruitment to the population [29]. Age of maturity and timing of spawning for Atlantic Sturgeon are dependent on latitude with northern populations reaching sexual maturity between 20 and 25 years of age [29]. Between spawning, which occurs every 1-4 years, adult Atlantic Sturgeon migrate along the Atlantic coast to feed in non-natal estuaries and tidal embayments in the spring and summer and south during the fall and winter [30]. Starting in May each year approximately 10,000 Atlantic Sturgeon migrate through Minas Passage (MP) into Minas Basin (MB; [31]), Nova Scotia, to feed on abundant benthic invertebrates in the tidal flats [32]. Genetic analyses indicate that the summer feeding aggregation of Atlantic sturgeon in MB is composed of sturgeon from several populations. Sixty-one percent of Atlantic Sturgeon collected with trawls and weirs in $\mathrm{MB}$ originated from the SJR, 34\% from the Kennebec River (KR), 2\% from the Hudson River, New York, and 1\% from the James River, Virginia [33].

The KR population of Atlantic Sturgeon has been reported to enter MB earlier in June than the SJR population, and both populations depart during September [34]. Atlantic Sturgeon spend most of their time in the Southern Bight of MB and individuals have been captured together during consecutive sampling years [34]. It is unknown whether the Atlantic Sturgeon captured together were from the same population, and whether they remained together outside of MB [34].

Atlantic Sturgeon from the same population are subject to many stressors throughout their migratory range, including mortality due to bycatch in trawl and gill net fisheries throughout the mid-Atlantic Bight, US [35] and the potential future installation of in-stream tidal power in important migratory corridors. Understanding the cooccurrence patterns of Atlantic Sturgeon is important to help determine if one population or cohort could be disproportionately affected by anthropogenic stressors, such as fisheries' by-catch [36], or interaction with coastal 
engineering projects such as tidal turbines [37], and will hopefully lead to important management discussions about the protection of transboundary species. For larger free-ranging fishes, forming social groups has been predicted to assist in the guided learning of essential habitats [38]. In this study, we sought to (1) describe patterns in co-occurrences between Atlantic Sturgeon aggregating within $\mathrm{MB}$, and assess whether Atlantic Sturgeon form social groups, and (2) to determine if aggregations were more likely to form between individuals from the population or with the same initial capture date.

\section{Results}

Atlantic Sturgeon attributes Minas Passage/Minas Basin During 2010 to 2014, 103 Atlantic Sturgeon were captured via research directed otter trawl $(n=78)$ and brush weir $(n=25)$. Sturgeon had an average $( \pm$ SD $) L_{\mathrm{F}}$ of $134.49 \pm 2.03 \mathrm{~cm}$. Atlantic Sturgeon were detected within MB from May to October but detections peaked during May and July (Fig. 1). The mean $( \pm S D)$ number of days that Atlantic Sturgeon were detected within MB during 2012-2014 ranged between 5.9 \pm 5.8 (2014) and $14.6 \pm 10.8$ (2012; Table 1). Most detected Atlantic Sturgeon within MB were genetically assigned to the SJR and classified as sub-adults $\left(<150 \mathrm{~cm} L_{\mathrm{F}}\right.$; Table 1$)$. During 2014, tags implanted in sturgeon between 2010 and 2013 were still active.

\section{Social network analysis}

Atlantic Sturgeon appeared to experience considerable spatial overlap in the time they spent within MB, suggesting that there were enough data to test whether Atlantic Sturgeon preferentially co-occur (Fig. 2). The number of Atlantic Sturgeon dyads detected within MB peaked at 339 in 2012. Most Atlantic Sturgeon detected within MB co-occurred with another specimen but exhibited a low degree of co-occurrence (Table 2; Fig. 3).

\begin{tabular}{|c|c|c|c|c|}
\hline Year & No. of Sturgeon & KR (\%) & SJR (\%) & Mean No. days \\
\hline 2012 & 59 & 32 & 68 & $14.6 \pm 10.8$ \\
\hline 2013 & 50 & 26 & 74 & $6.2 \pm 5.8$ \\
\hline 2014 & 50 & 26 & 74 & $5.9 \pm 5.8$ \\
\hline
\end{tabular}

In $\mathrm{MB}$, the average number of co-occurrences was highest in 2012; however, the average SRI was below 0.10 (Table 2; Fig. 3). The low strength of the simple ratio index (SRI) in most years analyzed suggests that Atlantic Sturgeon had a low likelihood of spatio-temporal overlap with others while in the proximity of an acoustic receiver. Excluding 2014 (SRI, Coefficient of Variation $(C V)=5.48$, random $\mathrm{CV}=5.20, p=0.25$ ), the coefficient of variation was significantly higher than the null networks during 2012 (SRI, CV $=3.05$, random $C V=1.77, p=1.80 \times 10^{-3}$ ) and very close to significant during 2013 (SRI CV $=5.68$, random $\mathrm{CV}=4.30, p=0.06$ ).

\section{Co-occurrences and Atlantic Sturgeon attributes}

More than $50 \%$ of dyads detected within MB during 2012-2014 consisted of individuals from the same genetic river of origin. However, most dyads were captured on different days (Table 2). The results from MRQAP-DSP regression indicated that genetic river of origin and initial capture dates were not predictors of the presence of a co-occurrence within MB (Table 3).

\section{Discussion}

Atlantic Sturgeon formed co-occurrences within MB that were significantly different than would be observed by chance. Atlantic Sturgeon form large aggregations within feeding locations and this study provided evidence

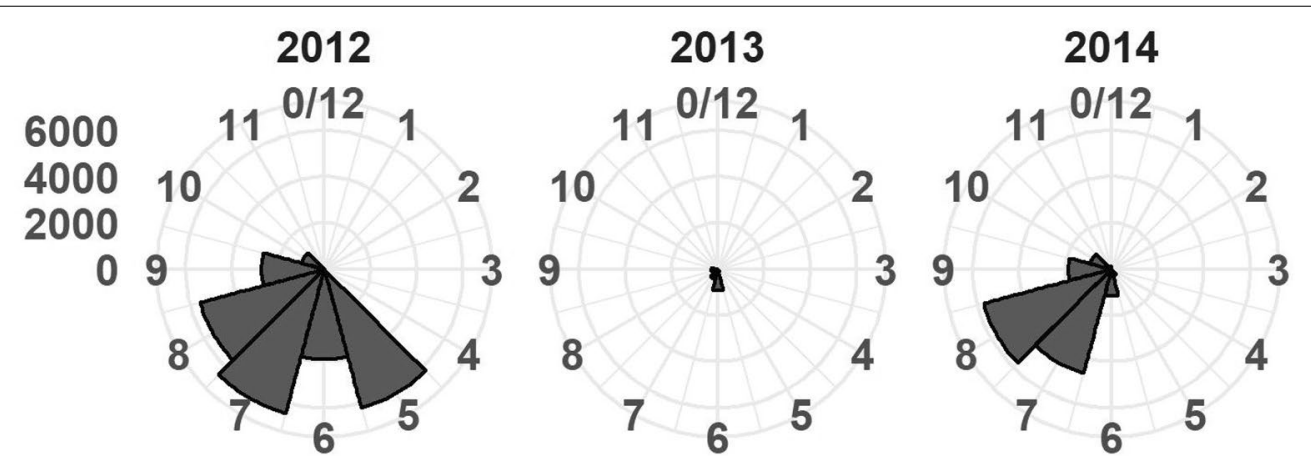

Fig. 1 Month of detections of Atlantic Sturgeon detected at VEMCO VR2W-69 kHz receivers deployed within Minas Basin during 2012-2014 


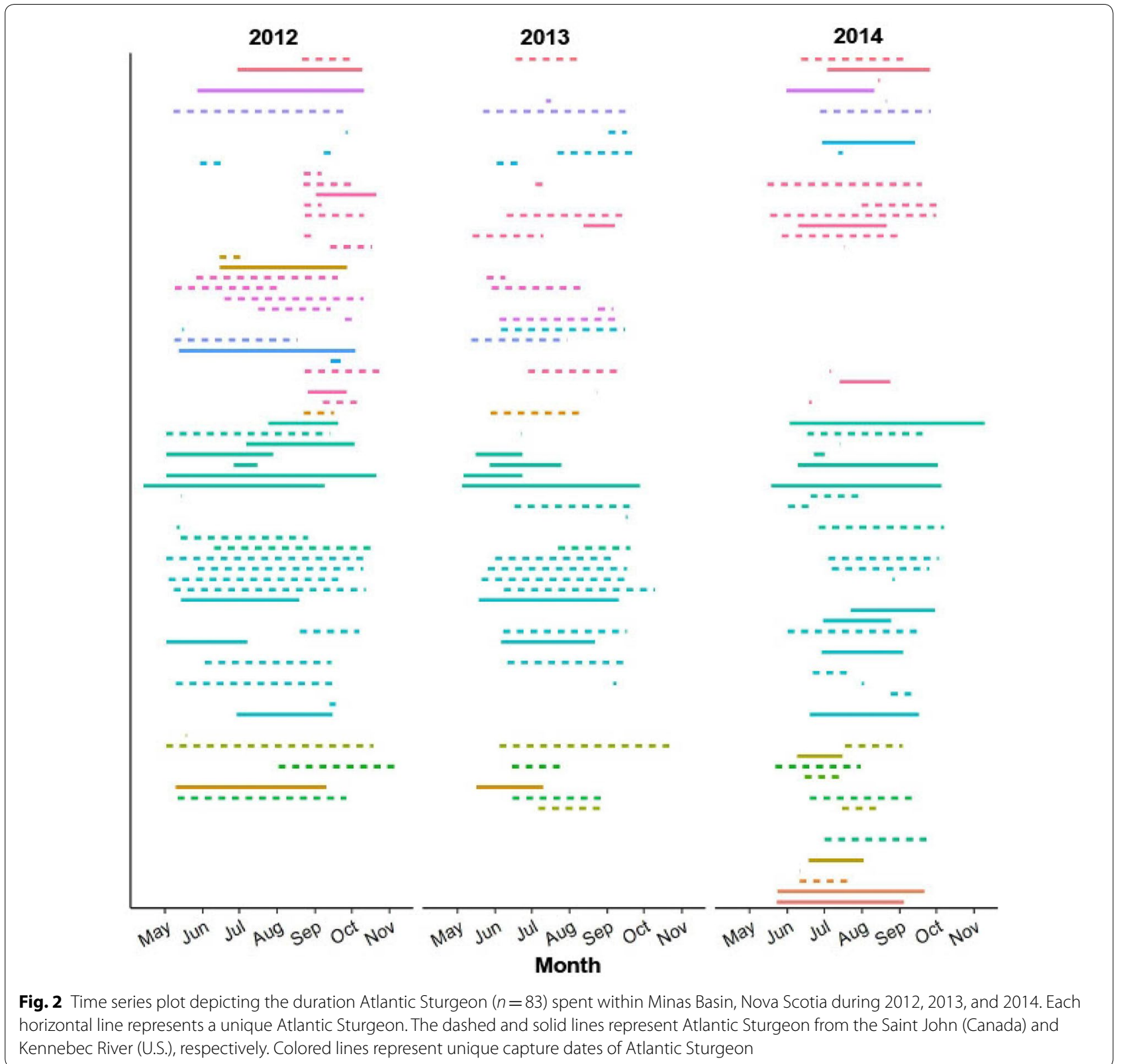

Table 2 Description of dyads detected within Minas Basin during 2012-2014, including the mean ( \pm Standard Deviation; $S D)$ simple ratio index (SRI), the mean $( \pm S D)$ nodal degree, and the characteristics of the dyads (genetic river of origin and initial capture date)

\begin{tabular}{|c|c|c|c|c|c|c|c|c|}
\hline \multirow[t]{2}{*}{ Year } & \multirow[t]{2}{*}{ Location } & \multirow[t]{2}{*}{ Mean SRI } & \multirow[t]{2}{*}{ Mean degree } & \multirow{2}{*}{$\begin{array}{l}\text { Total no. } \\
\text { of dyads }\end{array}$} & \multicolumn{2}{|l|}{ Genetic } & \multicolumn{2}{|c|}{ Capture date } \\
\hline & & & & & $\%$ same & $\%$ different & $\%$ same & $\%$ different \\
\hline 2012 & $M B$ & $0.08 \pm 0.08$ & $13.04 \pm 8.76$ & 339 & 55 & 45 & 12 & 88 \\
\hline 2013 & $M B$ & $0.17 \pm 0.17$ & $4.47 \pm 4.24$ & 76 & 66 & 34 & 12 & 88 \\
\hline 2014 & $M B$ & $0.15 \pm 0.13$ & $3.68 \pm 2.92$ & 92 & 52 & 48 & 13 & 87 \\
\hline
\end{tabular}




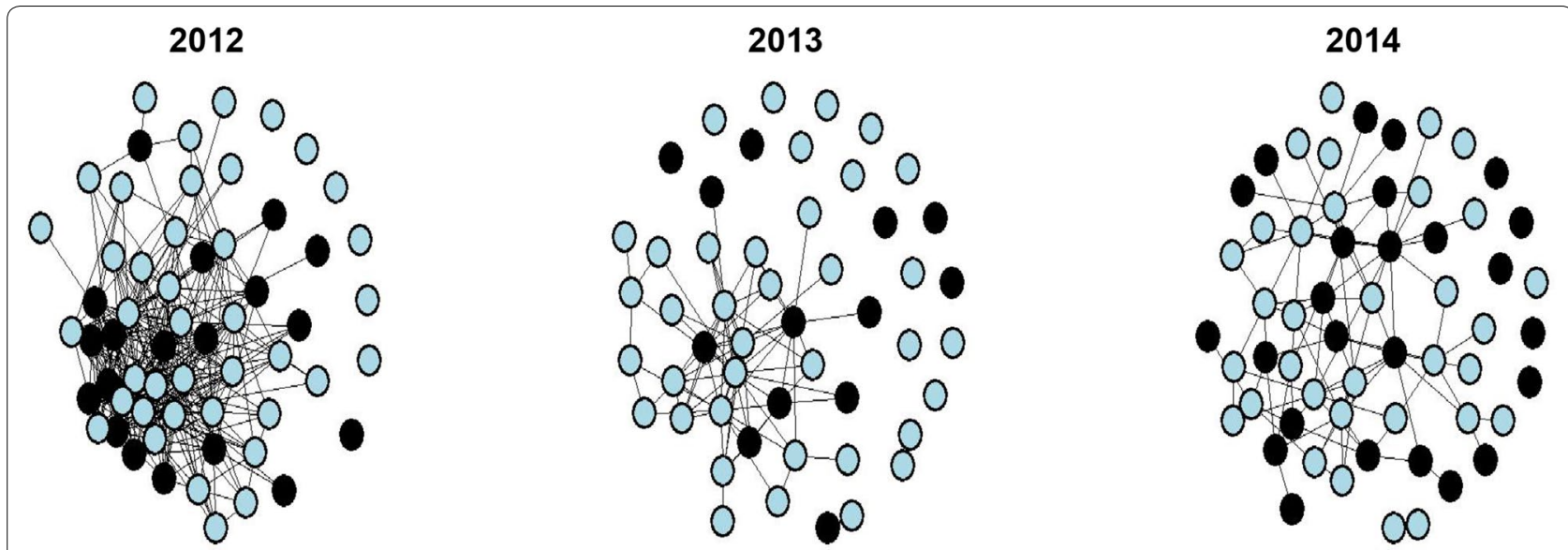

Fig. 3 Co-occurrence networks of acoustically tagged Atlantic Sturgeon $(n=83)$ with node representing fish detected within Minas Basin during 2012-2014. Blue and black nodes represent Atlantic Sturgeon from the Saint John and Kennebec River, respectively. Nodes are connected to one another via an edge; the edge represents the formation of a dyad

Table 3 Results from MRQAP-DSP regression displaying the effect of genetic river of origin (genetic), and initial capture date (capture) on the presence of co-occurrences of during 2012-2014

\begin{tabular}{|c|c|c|c|c|c|c|}
\hline \multirow[t]{2}{*}{ Predictor } & \multicolumn{2}{|l|}{2012} & \multicolumn{2}{|l|}{2013} & \multicolumn{2}{|l|}{2014} \\
\hline & Coefficient & $p$ & Coefficient & $p$ & Coefficient & $p$ \\
\hline Genetic & $-2.0 \times 10^{-4}$ & 0.93 & $1.2 \times 10^{-3}$ & 0.72 & $4.1 \times 10^{-3}$ & 0.06 \\
\hline Capture & $5.0 \times 10^{-3}$ & 0.93 & $-4.8 \times 10^{-3}$ & 0.35 & $2.0 \times 10^{-3}$ & 0.45 \\
\hline
\end{tabular}

All predictors were not significantly correlated with the presence of a co-occurrence during each of the years analyzed. In addition, the variance explained by the models was extremely low $\left(2012: R^{2}=1.3 \times 10^{-2}, 2013: R^{2}=8.5 \times 10^{-4}, 2014: R^{2}=2.40 \times 10^{-3}\right)$

that some Atlantic Sturgeon preferentially co-occur with other individuals. Sturgeons' co-occurrence behavior may be similar to that reported for several species of shark [39-41] which have been thought to undergo solitary marine migrations but preferentially co-occur at feeding sites [5]. Most behavioral studies examining cooccurrence behavior have focused on teleost fishes $[6,10]$ and may not be directly comparable to more primitive chondrostei such as the Atlantic Sturgeon.

\section{Atlantic Sturgeon co-occurrence}

The mean number of co-occurrences between individuals was found to be high within MB. Receivers within $\mathrm{MB}$ are located on mudflats where Atlantic Sturgeon aggregate during high tide and retreat during low tide [42]. Despite the highest receiver coverage in MB, 2012 had the greatest number of co-occurrences, but the lowest mean SRI, providing evidence that association strength is weak within $\mathrm{MB}$. In addition, the $\mathrm{CV}$ of detected cooccurrences of Atlantic Sturgeon within MB was significantly higher than would be expected by chance during 2012 and very close to significant during 2013, but this was not the case in 2014. In this study, we were only able to describe patterns in co-occurrences between Atlantic
Sturgeon, and unable to characterize social interactions [6]. This is due to the inability to record interactions with acoustic telemetry data since it only provides information regarding when individuals co-occur. However, there is evidence that some individuals may preferentially cooccur which is a requirement for the formation of social groups [5].

Klimley and Holloway [6] noted that if individuals display a tendency for preferential co-occurrences then they should be captured on the same day and return to the same locations successively. Within MB Atlantic Sturgeon were almost equally as likely to form co-occurrences with individuals captured on the same versus different days, or same versus different genetic river of origin. This indicates that Atlantic Sturgeon do not form preferential co-occurrences with individuals that have similar life history characteristics. However, future studies should increase receiver coverage over time and include more tagged individuals, to determine if sturgeon preferentially co-occur with kin or familiar individuals.

Species that exhibit social preferences tend to aggregate with familiar individuals regardless of environmental drivers [15]. The formation of social groups has been more commonly recognized in species that exhibit 
strong site fidelity, such as Blacktip Reef Sharks, Carcharhinus melanopterus (Quoy \& Gaimard, 1824) and the Spotted Wobbegong Shark (Orectolobus maculatus, Bonnaterre, 1788) $[4,15]$. Grouping with familiar individuals in dense aggregation regions may help to corral prey and protect against aggression from conspecifics $[4,15]$. Mourier et al. [15] noted that Blacktip Reef Sharks displayed some association preferences, exhibiting similar home ranges with individuals of similar size and sex regardless of food resource availability. The Spotted Wobbegong Shark exhibits long term co-occurrences with the same individual, regardless of the presence of high densities of other individuals [4]. A more solitary species, the Sand Tiger Shark (Carcharias Taurus Rafinesque, 1810) undergoes solitary marine migrations but aggregates with conspecifics for prolonged periods in ecologically important areas, spending multiple days near specific individuals [40]. However, it is unknown whether these sharks were actively engaging in social preference or just utilizing a food resource [40]. Atlantic Sturgeon also undergo extensive marine migrations and have been known to aggregate with others for prolonged periods at feeding sites, breeding, and overwintering sites [3, 43-45]. Our current study contributed to this body of work by identifying that Atlantic Sturgeon aggregate with conspecifics and that some individuals exhibit preferential co-occurrences.

The formation of preferential co-occurrences exhibited by Atlantic Sturgeon in our study have also been reported in white sharks (Carcharodon carcharias Linnaeus, 1758). Schlids et al. [5] noted that white sharks, while known to be solitary, form aggregations within feeding zones such as pinniped colonies. Furthermore, within these feeding zones they exhibit preferential cooccurrences. Unlike teleost species such as the Atlantic Bluefin Tuna (Thunnus thynnus Linnaeus, 1758), white sharks have few natural predators and do not require the protection of a shoal of familiar individuals throughout their marine migration [46].

The only known natural predator of Atlantic Sturgeon adults is the white shark, and a small number migrates annually into the Bay of Fundy [46]. The lack of natural predators may explain why these two species undergo solitary marine migrations. Findlay et al. [39] hypothesized that white sharks may aggregate at specific locations due to food availability. Atlantic Sturgeon are also known to aggregate within Minas Basin to feed on benthic polychaetes which are found in high densities [33, 47]. For solitary migratory species, aggregating with familiar individuals within feeding sites may be beneficial to facilitate the transfer of knowledge of foraging strategies, and the location of prey from experienced fishes to naïve individuals.
The finding that Atlantic Sturgeon can form preferential co-occurrences may also be related to sturgeon following a similar migratory route around MB. MP connects MB to the Bay of Fundy, and approximately 14 billion tons of water flows through MP during each flood tide, and the high flow through the MP creates a residual current of $0.8 \mathrm{~m} / \mathrm{s}$ within $\mathrm{MB}$ [48]. The residual current flows around $\mathrm{MB}$ in a clockwise direction, and it has been hypothesized that Atlantic Sturgeon follow this current. Future studies should expand the use of SNA within other known feeding, breeding and overwintering sites for Atlantic Sturgeon to determine whether our results may have been an artifact of the current circulation within MB.

This study provided evidence that Atlantic Sturgeon preferentially co-occur with each other when they form feeding aggregations; however, co-occurrences may not be linked to river of origin. This is a particularly important finding for migratory species from populations of varying conservation statuses to help inform management of transboundary species.

\section{Conclusion}

Understanding patterns in associative behavior in large free-ranging aquatic fishes, particularly those listed as threatened or endangered, is required to help better inform management decisions. This study indicates that combining SNA and acoustic telemetry data provides the means to assess patterns in spatio-temporal cooccurrence of fishes. The results of this study indicated that Atlantic Sturgeon may actively share time and space within their known summer feeding site located in $M B$, Nova Scotia. It is currently unknown how Atlantic Sturgeon locate ecologically essential habitats; however, it has been proposed that fishes can engage in social learning [38]. Future studies should expand receiver infrastructure to better characterize migratory patterns of the species and understand co-occurrence behaviors across a broader range of habitats and life-stages.

\section{Methods \\ Minas Basin (MB)}

The Bay of Fundy (BoF) is a region that extends between New Brunswick (NB) and Nova Scotia (NS), Canada. This region has the highest tides in the world, with a maximum amplitude of $17 \mathrm{~m}$ in Cobequid Bay [49-51]. The BOF is connected to $\mathrm{MB}\left(\sim 45^{\circ} 27^{\prime} 36^{\prime} \mathrm{N}, 64^{\circ} 18^{\prime} 12^{\prime} \mathrm{W}\right)$ through MP $\left(\sim 45^{\circ} 34^{\prime} 82^{\prime} \mathrm{N}, 64^{\circ} 39^{\prime} 27^{\prime} \mathrm{W}\right)$; a 5-km-wide, 15-km-long, 150-m-deep channel (Fig. 4) [49]. Tidal current speeds in this region reach up to $6 \mathrm{~m} / \mathrm{s}$ [52]. $\mathrm{MB}$ is a mega-tidal embayment located within NS, Canada, with an area of approximately 115,000 hectares [53]. Due to 


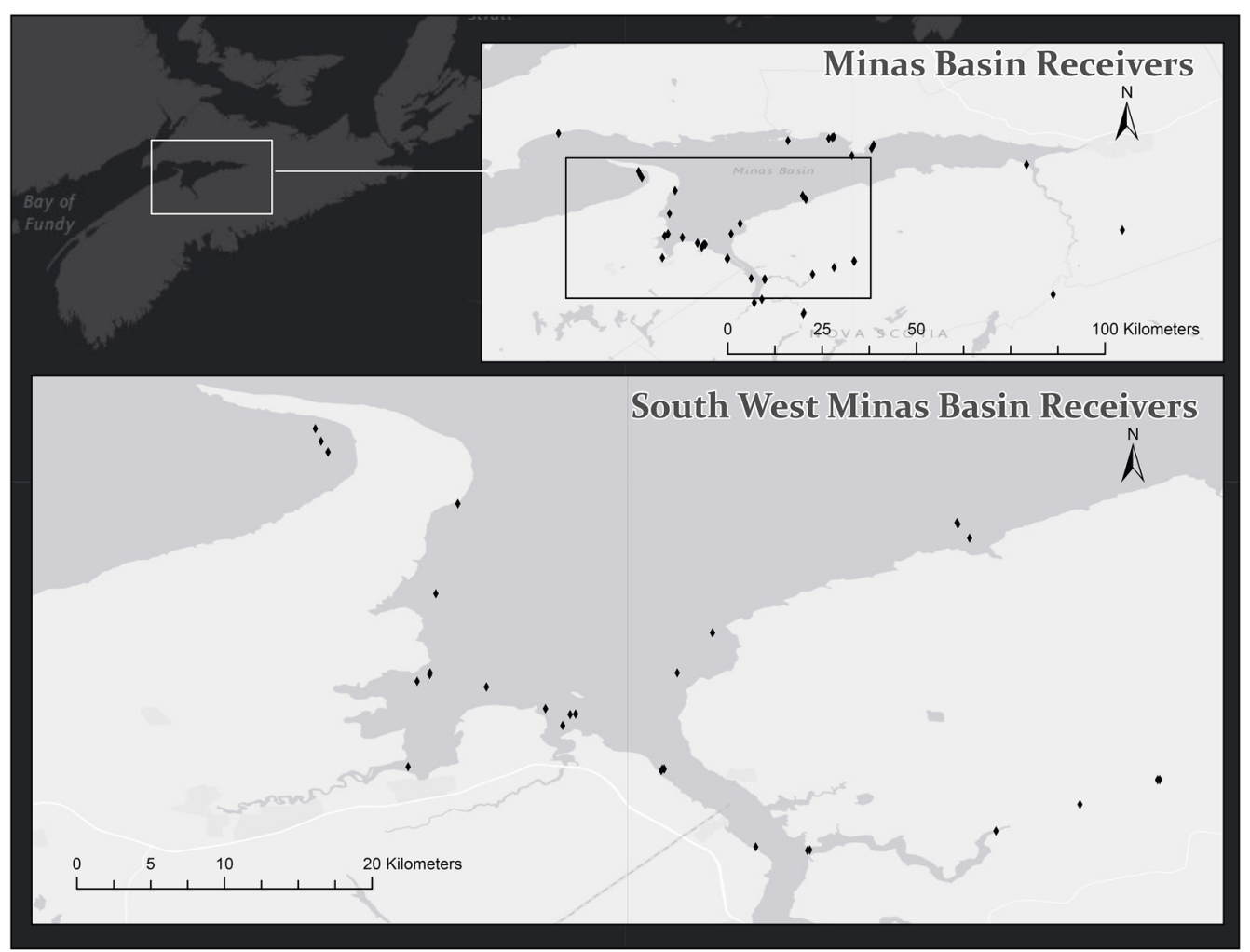

Esri, HERE, Garmin, (c) OpenStreetMap contributors, and the GIS user community

Fig. 4 Locations of VEMCO VR2W-69 kHz receivers deployed in Minas Basin (2012-2014; $n=17-13$ )

Table 4 Summary of V16-69 kHz tag types implanted in Atlantic Sturgeon that had genetic assignment during 2010$2014(n=103)$

\begin{tabular}{|c|c|c|c|c|c|c|}
\hline \multirow[t]{2}{*}{ Year } & \multirow[t]{2}{*}{ VEMCO tag type } & \multirow[t]{2}{*}{ Number deployed } & \multirow[t]{2}{*}{ Battery life (days) } & \multirow[t]{2}{*}{$\begin{array}{l}\text { Approx. tag death } \\
\text { (yyyy-mm) }\end{array}$} & \multicolumn{2}{|c|}{$\begin{array}{l}\text { Genetic assignment } \\
\text { (No. sturgeon) }\end{array}$} \\
\hline & & & & & KR & SJR \\
\hline \multirow[t]{3}{*}{2010} & V16-6x & 10 & 1633 & 2015-02 & 4 & 6 \\
\hline & V16P-6x & 10 & 1287 & 2014-02 & 2 & 8 \\
\hline & V16TP-6x & 5 & 1609 & 2015-01 & 1 & 4 \\
\hline 2011 & V16P-6x & 53 & 1287 & 2015-01 & 26 & 27 \\
\hline 2012 & V16P-6x & 15 & $1287 / 1581$ & 2016-04/2016-12 & 5 & 10 \\
\hline 2013 & - & - & - & - & - & - \\
\hline 2014 & V16P-6x & 10 & 2751 & $2021-12$ & 5 & 5 \\
\hline
\end{tabular}

Atlantic Sturgeon were not tagged during 2013

the extreme tides in $\mathrm{MB}$, shorelines and sandstone cliffs are eroded, contributing to high turbidity $[53,54]$.

\section{Atlantic Sturgeon capture and sampling}

During 2010 to 2014 Atlantic Sturgeon were captured through directed otter trawl and weir fishing and internally implanted with acoustic tracking tags (Table 4). The trawl consisted of a 24-m box trawl with a $140 \mathrm{~mm}$ mesh size and modified rock hopper equipment [31] and trawls ranged between 30 and $60 \mathrm{~min}$. A fishing weir is a large $\mathrm{V}$-shaped net, constructed in the intertidal zone with wings extending up to $1 \mathrm{~km}$ and with walls approximately $2.2 \mathrm{~m}$ in height [55]. During high tide the walls of the weir are submerged. During ebbing tide, fish are funneled by the walls to a trap located where the two wings merge 
[55]. Atlantic Sturgeon were released from the weirs into a holding pool for sampling.

In 2010 and 2011, Atlantic Sturgeon were captured by research-directed trawl in MB near Cheverie (Fig. 5). In 2012 trawls occurred in the Southern Bight, off Cambridge. In addition, during 2010 and 2011, Atlantic Sturgeon were captured at the Five Islands weir in MB. Atlantic Sturgeon also captured at the Bramber Weir located in the Southern Bight of MB in 2014 (Fig. 5).

\section{Acoustic tagging}

Atlantic Sturgeon were measured for fork length $\left(L_{\mathrm{F}}\right)$ and total length $\left(L_{\mathrm{T}} ; \mathrm{cm}\right)$, and externally implanted with a FLOY dart tag with a unique number and a return address (Floy Tag \& Manufacturing Inc., Seattle, Washington). Floy tags were inserted under the dorsal fin and anchored through the pteriogyte bone [31]. Each Atlantic Sturgeon was internally implanted with a V16-69 kHz VEMCO acoustic tag (Table 4). The V16 tags had an estimated battery life that ranged between 1287 and 2751 days and were set to emit 8 burst pings at $69 \mathrm{kHz}$ with a nominal delay of $75 \mathrm{~s}$. The acoustic power level was set to high (158 dB).

Anesthetic was not used for surgeries as it increases handling time and has been shown to increase postrecovery cortisol levels in Atlantic Sturgeon [56]. For the surgery procedure sturgeon were placed on their dorsal side. The area on their ventral side where the incision occurred was disinfected with $10 \%$ Betadine ${ }^{\mathrm{TM}}$ solution and rinsed with a $0.9 \%$ sodium chloride solution [34]. A 30-mm lateral incision was made $40-60 \mathrm{~mm}$ anterior to the pelvic fin near the linea alba $[42,57]$. Sutures were tied in double square knots [57]. All handling and surgical procedures occurred in $<15 \mathrm{~min}$.

All fishing was conducted under the Department of Fisheries and Oceans Scientific License to Fish \#322595. Atlantic Sturgeon surgical procedures were performed under Acadia Animal Care Committee protocol \#07-11.

\section{Determining life history characteristics \\ Genetic analysis}

Each Atlantic Sturgeon collected from MB was assigned a spawning river of origin using Individual-Based Assignment (IBA) testing implemented in ONCOR [58] as originally described for Atlantic Sturgeon in the BOF in Wirgin et al. [33] and subsequently in Stewart et al. [59] ONCOR assigned individuals in the mixed MB collections to the reference population that would have the highest probability of producing the given genotype in the mixture. ONCOR uses the method of Rannala and Mountain [60] to estimate this probability.

Assignments were based on a combination of microsatellite DNA genotypes at 11 informative loci and mtDNA control region sequencing data. Composite genotypes of $\mathrm{MB}$ individuals were compared to those of a reference collection set of 1295 subadult $(\leq 50 \mathrm{~cm} \mathrm{TL})$ and adult $(\geq 130 \mathrm{~cm}$ TL) specimens collected from 11 spawning rivers coastwide ranging from the St. Lawrence River,

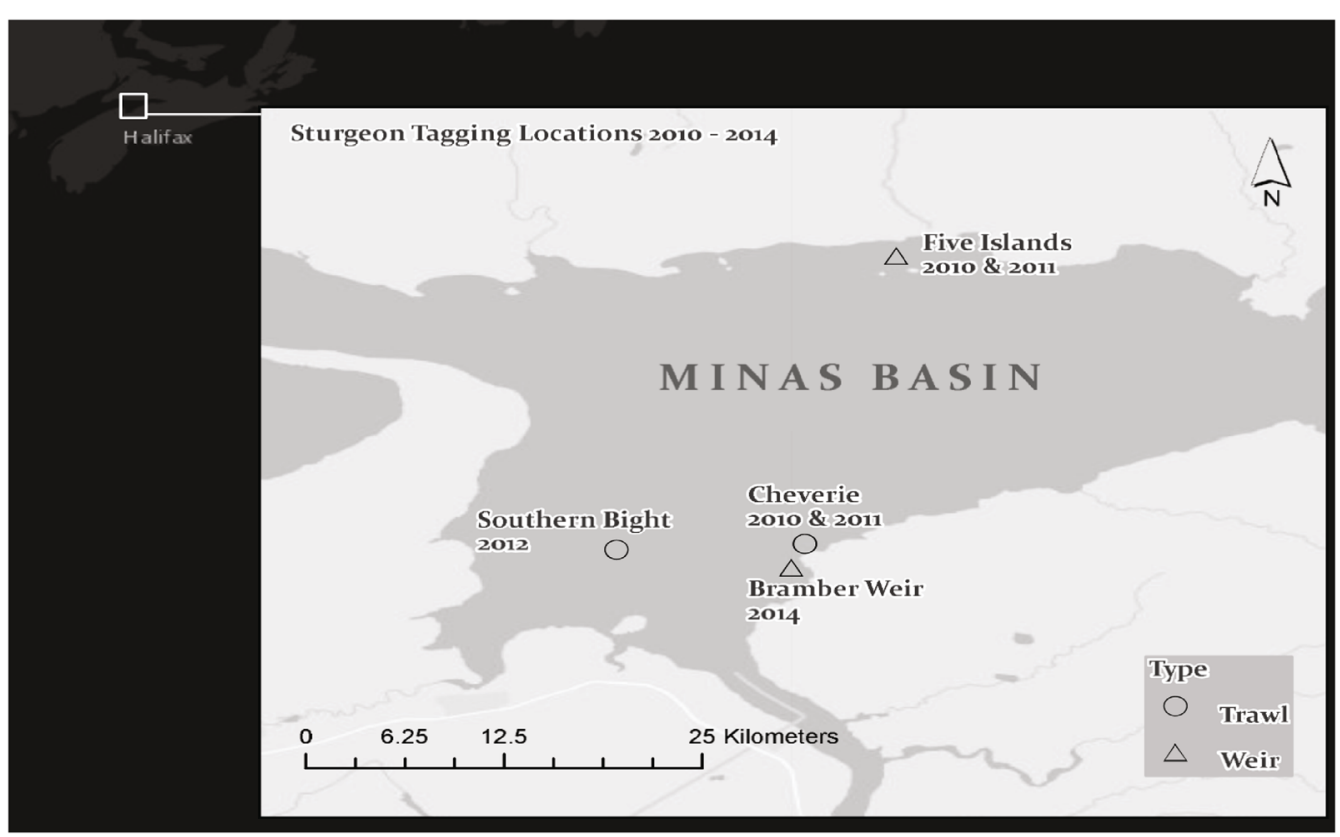

Fig. 5 Locations of research directed otter trawls and weirs used within Minas Basin (MB) for Atlantic Sturgeon capture during $2010-2014$ 
Quebec, to the Altamaha River, Georgia exactly as described in Stewart et al. [59]. While mean assignment accuracy to individual population coastwide in leaveone-out tests implemented in ONCOR [58] was 85.8\%, assignment accuracy to the Saint John River was much higher at $97.8 \%$ with most misassignments occurring for the proximal Kennebec River. All DNA was isolated from fin clips that were preserved in 95\% ethanol. All genotyping was done at NYUMC laboratory exactly as described in Wirgin et al. [61].

\section{Acoustic receivers}

Acoustic tagging data were collected from VR2W-69 kHz receivers in MB during 2012-2014 (Fig. 3, Table 2). Receiver coverage in MB varied by year; however, each year receivers were deployed in areas where Atlantic Sturgeon are known to aggregate in high densities [42]; Fig. 3; Table 5). Range test procedures are described in McLean et al. [42]. The estimated range of VR2W-69 kHz receivers within $\mathrm{MB}$ was $500 \mathrm{~m}$.

\section{Analysis of acoustic data Filtering false detections}

Acoustic data were filtered for false detections using the GLATOS package [62] in $\mathrm{R}$ version 3.5.0 [63]. Detections that did not correspond to any tag ID recognized by VEMCO were removed, and the data were then filtered for Atlantic Sturgeon detections.

The genetic origin of Atlantic Sturgeon detected by the MB receivers during 2012 to 2014 was recoded to values that represented the river of origin of the fish. If an Atlantic Sturgeon individual was not given a genetic assignment, then it was removed from the dataset. Atlantic Sturgeon genetically assigned to the KR were classified as 1 and Atlantic Sturgeon genetically assigned to the SJR were classified as 2 .

\section{Social analyses}

Our acoustic data at each receiver were represented by $D=\left\{S_{z}, t_{z}, l_{z}\right\}_{z=1}^{Z}$, where $\mathrm{Z}$ was the total number of Atlantic Sturgeon detected at one acoustic receiver during each year (2012-2014), $S_{z}$ was equal to the ID code

Table 5 Time periods VEMCO VR2W-69 kHz receivers were deployed within Minas Basin (MB), Nova Scotia during 2012-2014

\begin{tabular}{llllll}
\hline $\begin{array}{l}\text { Receiver } \\
\text { location }\end{array}$ & $\begin{array}{l}\text { Months } \\
\text { deployed }\end{array}$ & Approx. range & \multicolumn{3}{l}{ No. of receivers } \\
\cline { 3 - 6 } & Apr-Nov & $500 \mathrm{~m}$ & 17 & 11 & 13 \\
\hline MB & & & $\mathbf{2 0 1 2}$ & $\mathbf{2 0 1 3}$ & $\mathbf{2 0 1 4}$ \\
\hline
\end{tabular}

for one Atlantic Sturgeon, $t_{z}$ was the time at which an individual sturgeon was detected at a receiver, and $l_{z}$ was the location of each receiver. Co-occurrences were defined based on the temporal difference in arrival at an acoustic receiver. To define spatio-temporal co-occurrences, the $\mathrm{R}$ package asnipe [64] was used. Co-occurrences were defined based on the "gambit of the group assumption"-interactions between members of populations are not apparent, and if individuals are in close enough spatiotemporal proximity to one another to interact, then they were assigned to the same group and designated as co-occurring $[22,65,66]$. To ensure that we were able to accurately define the network of Atlantic Sturgeon within $\mathrm{MB}$, we removed data from individuals with less than five detections [15]. This procedure has been used in several SNA studies [5, 39]. Using the "gambit of the group" approach requires defining the spatiotemporal proximity in which individuals could be assumed to be co-occurring [67].

\section{Social network analysis}

Associations were defined based on individuals being detected within an 11-h sampling period at a receiver during a 24-h interval. A sampling period is the duration between co-occurrence of two individuals at an acoustic receiver, if two individuals are detected within a sampling period then they are assumed to co-occur [25]. An interval is the time allotted between sampling periods [25]. An interval is used to ensure that co-occurrence strength is not exaggerated and to allow for re-organization of the network [25, 39]. An interval of 1 day was chosen for this study.

Co-occurrences within each study location were defined using the Simple Ratio Index (SRI), and were calculated using the package asnipe [64]. Here, the SRI is represented by

$$
\mathrm{SRI}=\frac{x}{x+y_{A B}+y_{A}+y_{B}}
$$

where $x$ is the number of sampling periods where cooccurrences are scaled between 0 (never observed in the same group) and 1 (always occurred in the same group). $Y_{A B}$ is the number of sampling periods in which both Atlantic Sturgeon were detected but at different locations, $Y_{A}$ is the number of sampling periods where only sturgeon $A$ was detected and $Y_{B}$ is the number of sampling periods where only sturgeon $B$ was detected [68].

The SRI ranges between 0 and 1 , where 1 indicates that individuals' strong co-occurrences and values near zero indicate that Atlantic Sturgeon exhibited weak cooccurrences $[17,65]$. The SRI was chosen over other indices as acoustic detection data are unlikely to violate the 
assumptions of the SRI. The assumptions state that each individual tracked within the study has an equal opportunity of being detected regardless of whether they formed co-occurrences, and the detection of one individual implies that its associates will also be detected within the sampling period [10, 17]. A concern when using acoustic detection data for SNA is that receivers can have variable detection ranges depending on environmental conditions. Variable detection range may inhibit the assignment of a co-occurrence if one individual is slightly out of range. This study used temporal differences in time stamps that greatly exceeded the tag's nominal delay, decreasing the risk of violating the assumption of equal detection opportunities [10].

\section{Selecting a sampling period}

In this study, sampling periods were determined by performing a sensitivity analysis, comparing co-occurrences defined based on temporal differences of $15 \mathrm{~min}, 30 \mathrm{~min}$ and between 1 and $24 \mathrm{~h}$, accounting for 26 calculations of SRIs $[4,39]$. Thirty-one pairs of Atlantic Sturgeon ( 10\%) exhibiting the highest co-occurrence strengths from the 15-min network during 2012 were selected for analysis. The SRI fluctuated between $15 \mathrm{~min}$ and $11 \mathrm{~h}(660 \mathrm{~min})$ and then for most dyads stabilized after $11 \mathrm{~h}$ (Fig. 6); therefore, an 11-h sampling period was chosen for analysis [4]. Atlantic Sturgeon are known to aggregate at specific locations within $\mathrm{MB}$ for multiple days; therefore, it is still likely that they could remain within close spatialtemporal proximity during a sampling period of $11 \mathrm{~h}$ (Dr. M. Dadswell, Acadia University, Wolfville, Nova Scotia, oral communication, 2018).

\section{Testing for preferred co-occurrences}

To test whether Atlantic Sturgeon form preferred or random co-occurrences within $\mathrm{MB}$, we compared the observed co-occurrence indices to those calculated from permuted networks for each year (2012-2014) [17]. Permutations involved swapping sturgeon between groups at the same receiver location and recalculating the SRI after randomizations [25]. The coefficient of variation $(\mathrm{CV})$ of the SRI from the permuted networks was compared to the observed network, and a $p$ value was calculated by determining the total number of times the $\mathrm{CV}$ of the observed network was less than the CV of the randomized networks and dividing by the number of permutations $(n=40,000)$ [25]. Forty thousand permutations were used to stabilize the $p$ values for data from MB [10]. The population of Atlantic Sturgeon was assumed to exhibit preferred co-occurrences if their $\mathrm{CV}$ was greater than the $97.5 \%$ of the permuted CVs [39]. Social differentiation $(S)$ represents the $\mathrm{CV}$ of the observed networks. Due to the high social differentiation $(S)$ of the

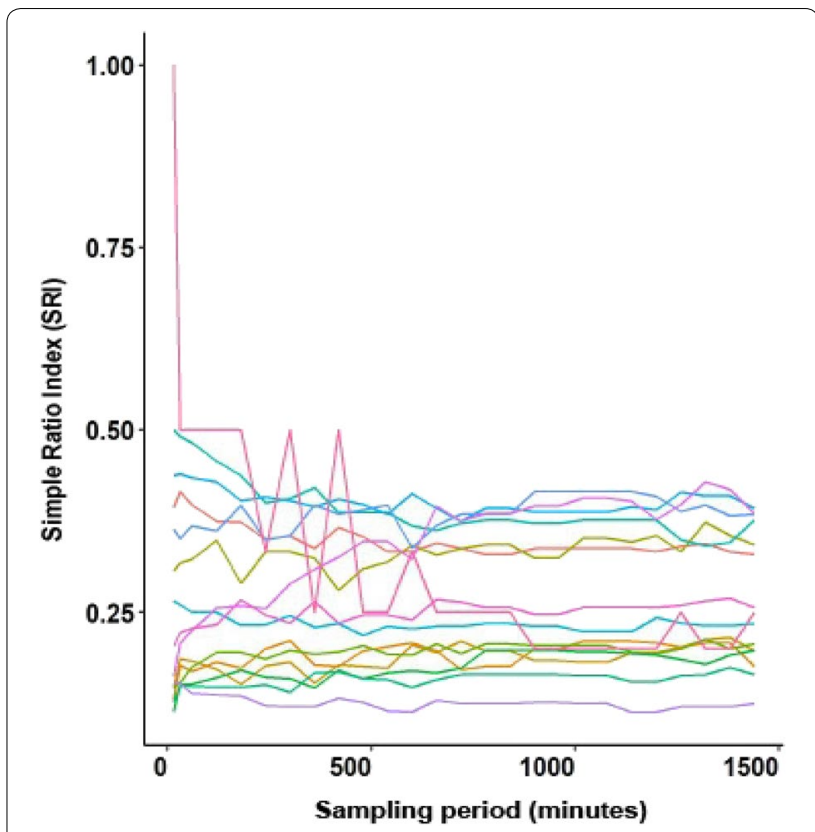

Fig. 6 Sensitivity analysis, comparing the differences in strength of the Simple Ratio Index (SRI) with increasing sampling periods (5 to $1440 \mathrm{~min}$ ) for Atlantic Sturgeon dyads detected within Minas Basin during 2012. Each unique color refers to one dyad

observed networks $(S ; 2012-2014: 3.04,5.68,5.48)$, few co-occurrences per individual were required to reject the null hypothesis $(H ; 2012-2014: 7.39,1.24,1.79)$ [69]. Therefore, the power of the permutation tests conducted within MB during 2012-2014 $\left(S^{2} \times H>5 ; 68.30,7.04\right.$, 9.81) was sufficient to test for preferred co-occurrences [69].

\section{Influence of genetic river of origin and capture date on co-occurrence strength}

After extracting SRIs, Atlantic Sturgeon co-occurrences detected in MB (2012-2016) were categorized into subgroups consisting of those that had the same genetic river of origin (Kennebec/Kennebec, Saint John/Saint John) and those that had different genetic river of origins (Kennebec/ Saint John) and those captured on the same and different days, respectively. Using the double-semi-partitioning technique, Multiple Regression Quadratic Assignment Procedure (MRQAP) was run to determine whether matrices formed based upon the unique characteristics of dyads were predictors of co-occurrence strength within $\mathrm{MB}[70$, 71]. MRQAP was run with 20,000 permutations and the partial correlation coefficients of each predictor variable were extracted [70, 71]. The predictor matrices (genetic river of origin, capture date) were assessed for collinearity using Mantels tests (10,000 permutations) prior to analysis using the $R$ package vegan [72]. 


\section{Abbreviations}

SNA: Social network analysis; DU: Designatable units; SJR: Saint John River; DPS: Distinct population segments; MP: Minas Passage; MB: Minas Basin; KR: Kennebec River; BoF: Bay of Fundy; NB: New Brunswick; NS: Nova Scotia; IBA: Individual based assignment; OTN: Ocean Tracking Network; SUB: Streamlined subsurface buoys; SRI: Simple ratio index; CV: Coefficient of variation; MRQAP: Multiple regression quadratic assignment procedure.

\section{Acknowledgements}

The authors would like to acknowledge Captain Glanville and Charles Travis for capturing sturgeon by otter trawl, and Erica Porter, Darren Porter and Wayne Linkletter for capturing sturgeon by brush weir. We thank J. Broome, J. Beardsall, L. Logan-Chesney, S. Wehrell, C. Buhariwalla, G. Nau, N. Stewart, and the many other field assistants who provided field support. MJWS was supported by the Canada Research Chairs program.

\section{Authors' contributions}

MJWS and MJD designed the tagging program. MFM, MJWS, MJD, and JL completed the field work. IW conducted the genetic analysis. PDC created the maps. $J \mathrm{~L}$ analyzed and interpreted the data regarding social cohesion and dyad formation. $J L$ wrote the initial manuscript with contributions from MFM, MJD, and MJWS. All authors read the manuscript and provided critical review. All authors read and approved the final manuscript.

\section{Funding}

Thank you to the Ocean Tracking Network at Dalhousie University for providing much of the funding for the Atlantic Sturgeon tagging program through the Canada Foundation for Innovation and the National Science and Engineering Research Council funds to OTN. We also acknowledge support of the Molecular Facilities Core of New York University NIEHS Center Grant ES000260. MJWS was funded by the Canada Research Chairs program.

\section{Availability of data and materials}

The datasets used and/or analyzed during the current study are available from the corresponding author on reasonable request.

\section{Ethics approval and consent to participate}

All fishing was conducted under the Department of Fisheries and Oceans Scientific License to Fish \#322595. Atlantic Sturgeon surgical procedures were performed under Acadia Animal Care Committee protocol \#07-11.

\section{Consent for publication}

Not applicable.

\section{Competing interests}

The authors declare that they have no competing interests.

\section{Author details}

${ }^{1}$ Department of Biology, Acadia University, 33 Westwood Avenue, Wolfville, NS B4P 2R6, Canada. ${ }^{2}$ Department of Environmental Medicine, New York University School of Medicine, 341 East 25th St., New York, NY 10010, USA.

Received: 22 November 2019 Accepted: 28 April 2020

Published online: 14 May 2020

\section{References}

1. Krause J, Ruxton GD. Living in groups. Oxford: Oxford University Press; 2002.

2. Johnson DD, Kays R, Blackwell PG, Macdonald DW. Does the resource dispersion hypothesis explain group living? Trends Ecol Evol. 2002;17:563-70.

3. Taylor AD, Ohashi K, Sheng J, Litvak MK. Oceanic Distribution, behavior, and a winter aggregation area of adult Atlantic Sturgeon, Acipenser oxyrinchus oxyrinchus, in the Bay of Fundy. PLOS ONE. 2016;11(4):e0152470
4. Armansin NC, Lee KA, Huveneers C, Harcourt RG. Integrating social network analysis and fine-scale positioning to characterize the associations of a benthic shark. Anim Behav. 2016;115:245-58.

5. Schilds A, Mourier J, Huveneers C, Nazimi L, Fox A, Leu ST. Evidence for non-random co-occurrences in a white shark aggregation. Behav Ecol Sociobiol. 2019;73(10):138.

6. Klimley AP, Holloway CF. School fidelity and homing synchronicity of yellowfin tuna, Thunnus, albacares. Mar Biol. 1999;133:307-17.

7. Pinter-Wollman N, Hobson EA, Smith JE, Edelman AJ, Shizuka D, de Silva S, et al. The dynamics of animal social networks: analytical, conceptual, and theoretical advances. Behav Ecol. 2013;25:242-55.

8. Schluessel V. Who would have thought that 'Jaws' also has brains? Cognitive functions in elasmobranchs. Anim Cogn. 2015;18(1):19-37.

9. Mourier J, Bass NC, Guttridge TL, Day J, Brown C. Does detection range matter for inferring social networks in a benthic shark using acoustic telemetry? R Soc Open Sci. 2017:4(9):170485.

10. Stehfest KM, Patterson TA, Dagorn L, Holland KN, Itano D, Semmens JM. Network analysis of acoustic tracking data reveals the structure and stability of fish aggregations in the ocean. Anim Behav. 2013:85(4):839-48.

11. Croft DP, Krause J, James R. Social networks in the guppy (Poecilia reticulata). J R Soc Interface. 2004;271:S516-9.

12. Croft DP, James R, Thomas POR, Hathaway C, Mawdsley D, Laland KN, et al. Social structure and co-operative interactions in a wild population of guppies (Poecilia reticulata). Behav Ecol Sociobiol. 2006;59(5):644-50.

13. Croft DP, Darden SK, Ruxton GD. Predation risk as a driving force for phenotypic assortment: a cross-population comparison. Proc R Soc B. 2009;276:1899-904

14. Gaffney KA, Webster MM. Consistency of fish-shoal social network structure under laboratory conditions. J Fish Biol. 2018;92:1574-89.

15. Mourier J, Vercelloni J, Planes S. Evidence of social communities in a spatially structured network of a free-ranging shark species. Anim Behav. 2012;83(2):389-401.

16. James R, Croft DP, Krause J. Potential banana skins in animal social network analysis. Behav Ecol Sociobiol. 2009;63:989-97.

17. Whitehead H. Analyzing Animal Societies. In: Analyzing animal societies: quantitative methods for vertebrate social analysis. Chicago: University of Chicago Press; 2008.

18. Flack JC, Girvan M, de Waal FBM, Krakauer DC. Policing stabilizes construction of social niches in primates. Nature. 2006:439:426-9.

19. Fewell JH. Social insect networks. Science. 2003;301:1867-70.

20. Baird RW, Whitehead H. Social organization of mammal-eating killer whales: group stability and dispersal patterns. Can J Zool. 2000;78:2096-105.

21. Finn JT, Brownscombe JW, Haak CR, Cooke SJ, Cormier R, Gagne T, et al. Applying network methods to acoustic telemetry data: modeling the movements of tropical marine fishes. Ecol Model. 2014;293:139-49.

22. Jacoby DMP, Papastamatiou YP, Freeman R. Inferring animal social networks and leadership: applications for passive monitoring arrays. J R Soc Interface. 2016;13:20160676.

23. Hussey NE, Kessel ST, Aarestrup K, Cooke SJ, Cowley PD, Fisk AT, et al. Aquatic animal telemetry: a panoramic window into the underwater world. Science. 2015:348(6240):1255642.

24. Wippelhauser GS, Sulikowski J, Zydlewski GB, Altenritter MA, Kieffer M, Kinnison MT. Movements of Atlantic sturgeon of the Gulf of Maine Inside and outside of the geographically defined distinct population segment. Mar Coast Fish. 2017;9(1):93-107.

25. Farine DR, Whitehead $\mathrm{H}$. Constructing, conducting and interpreting animal social network analysis. J Anim Ecol. 2015;84(5):1144-63.

26. Vladykov VM, Greeley JR. Order Acipenseroidei. Contributions de la Departement des Pecheries Quebec. 1963;53(1):24-60.

27. NOAA. Endangered and threatened wildlife and plants; final listing for two distinct population segments of Atlantic sturgeon (Acipenser oxyrinchus oxyrinchus) in the southeast. FedReg. 2012;77:5914-82.

28. NOAA. Endangered and threatened wildlife and plants; threatened and endangered status for distinct population segments of Atlantic sturgeon in the northeast region. FedReg. 2012;77:5880-912.

29. Dadswell MJ. A review of the status of Atlantic Sturgeon in Canada, with comparisons to populations in the United States and Europe. Fisheries. 2006:31(5):218-29. 
30. Dunton KJ, Jordaan A, McKown KA, Conover DO, Frisk MG. Abundance and distribution of Atlantic sturgeon (Acipenser oxyrinchus) within the Northwest Atlantic Ocean, determined from five-fishery-independent surveys. Fish Bull. 2010;108(4):450

31. Dadswell MJ, Wehrell SA, Spares AD, Mclean MF, Beardsall JW, LoganChesney LM, et al. The annual marine feeding aggregation of Atlantic sturgeon in the inner Bay of Fundy: population characteristics and movement. J Fish Biol. 2016;89(4):2107-32.

32. McLean MF, Dadswell MJ, Stokesbury MJW. Feeding ecology of Atlantic Sturgeon, Acipenser oxyrinchus oxyrinchus Mitchill, 1815 on the infauna of intertidal mudflats of Minas Basin, Bay of Fundy. J Appl Ichthyol. 2013;29(3):503-9.

33. Wirgin I, Maceda L, Waldman JR, Wehrell S, Dadswell M, King T. Stock origin of migratory Atlantic sturgeon in Minas Basin, Inner Bay of Fundy, Canada, determined by microsatellite and mitochondrial DNA analyses. T Am Fish Soc. 2012;141(5):1389-98.

34. Logan-Chesney LM. Atlantic sturgeon population-specific movements residency and grouping behavior in Minas Basin Inner Bay of Fundy, Canada [master's thesis]. Wolfville (NS): Acadia University; 2016.

35. Stein AB, Friedland KD, Sutherland M. Atlantic Sturgeon Marine Distribution and Habitat Use along the Northeastern Coast of the United States. Trans Am Fish Soc. 2004;133(3):527-37.

36. Beardsall JW, McLean MF, Cooke SJ, Wilson BC, Dadswell MJ, Redden AM et al. Consequences of incidental otter trawl capture on survival and physiological condition of threatened Atlantic Sturgeon. Trans Am Fish Soc. 2013;142(5):1202-14.

37. Stokesbury MJW, Logan-Chesney LM, McLean MF, Buhariwalla CF, Redden AM, Beardsall JW, et al. Atlantic sturgeon spatial and temporal distribution in Minas Passage, Nova Scotia, Canada, a region of future tidal energy extraction. PLOS ONE. 2016;11(7):1-12.

38. Brown C, Laland KN. Social learning in fishes: a review. Fish Fisheries. 2003;4(3):280-8.

39. Findlay R, Gennari E, Cantor M, Tittensor DP. How solitary are white sharks: social interactions or just spatial proximity? Behav Ecol Sociobiol. 2016;70:1735-44

40. Haulsee DE, Fox DA, Breece MW, Brown LM, Kneebone J, Skomal GB, et al. Social network analysis reveals potential fission-fusion behavior in a shark. Sci Rep. 2016;6:34087.

41. Maximov V, Tiganov G, Paraschiv M. Preliminary data on the monitoring of sturgeon species in Romanian marine waters. J Environ Protect Ecol. 2014;15(3):933-43.

42. McLean MF, Simpfendorfer CA, Heupel MR, Dadswell MJ, Stokesbury MJW. Diversity of behavioral patterns displayed by a summer feeding aggregation of Atlantic sturgeon in the intertidal region of Minas Basin, Bay of Fundy, Canada. Mar Ecol Prog Ser. 2014;496:59-69.

43. Novak AJ, Carlson AE, Wheeler CR, Wippelhauser GS, Sulikowski JA. Critical foraging habitat of Atlantic Sturgeon based on feeding habits, prey distribution, and movement patterns in the Saco River Estuary, Maine. Trans Am Fish Soc. 2017;146(2):308-17.

44. Waldman JR, King T, Savoy T, Maceda L, Grunwald C, Wirgin I. Stock origins of subadult and adult Atlantic Sturgeon, Acipenser oxyrinchus, in a non-natal estuary, Long Island sound. Estuaries Coasts. 2013;36(2):257-67.

45. Altenritter MN, Zydlewski GB, Kinnison MT, Wippelhauser GS. Atlantic Sturgeon use of the Penobscot River and marine movements within and beyond the Gulf of Maine. Mar Coast Fish. 2017;9(1):216-30.

46. Department of Fisheries and Oceans (DFO). Recovery potential assessment report on White sharks in Atlantic Canada. 2006. Report No.: 52.

47. Featherstone RP, Risk MJ. Effect of tube-building polychaetes of intertidal sediments of the Minas Basin, Bay of Fundy. J Sediment Petrol. 1977:47:446-50

48. Godin G. The 1965 current survey of the Bay of Fundy-a new analysis of the data and an interpretation of the results. Manuscript Report Series. $1968 ; 8$.

49. Karsten R. An assessment of the potential of tidal power from Minas Passage, Bay of Fundy, using three-dimensional models. In: Proceedings of the 30th international conference on ocean, Offshore and Arctic Engineering, OMAE; 2011. p. 2011.

50. Dadswell MJ, Rulifson RA, Daborn GR. Potential impact of large-scale tidal power developments in the upper Bay of Fundy on fisheries resources of the Northwest Atlantic. Fisheries. 1986;11(4):26-35.
51. McMillan JM, Lickley MJ, Karsten R, Haynes R. The potential of tidal power from the Bay of Fundy. J Soc Ind Appl Math. 2008;1:20-37.

52. Karsten $R$, Swan $A$, Culina J. Assessment of arrays of in-stream tidal turbines in the Bay of Fundy. Phil Trans R Soc A. 2013;371:20120189.

53. Yeo RK, Risk MJ. Fundy tidal power environmental sedimentology. J Geol Assoc. 1979;6:115-21.

54. Percy JA. Fundy's Minas Basin: Multiplying the pluses of Minas. Granville Ferry: Nova Scotia, Bay of Fundy Ecosystem Partnership; 2001. p. 12.

55. Dadswell MJ, Spares AD, Porter E, Porter D. Diversity, abundance and size structure of fishes and invertebrates captured by intertidal fish weir at Bramber, Minas Basin, Nova Scotia. Proc N.S Inst Sci. 2020;50(2):283-318.

56. Matsche MA. Evaluation of tricaine methanesulfonate (MS-222) as a surgical anesthetic for Atlantic sturgeon Acipenser oxyrinchus oxyrinchus. J Appl Ichthyol. 2011;27:600-10.

57. Moser ML, Bain M, Collins MR, Haley N, Kynard B, O'Herron II JC, et al. A protocol for use of shortnose and Atlantic sturgeons. NOAA Tech Memo NMFS-OPR-18. 2000;18.

58. Kalinowski S, Manlove K, Taper M. ONCOR a computer program for genetic stock information [Internet]. Bozeman Montana: Montana State University; 2008. http://www.montana.edu/kalinowski/Software.htm.

59. Stewart ND, Cormier Y, Logan-Chesney LM, Gibson G, Wirgin I, Dadswell MJ, et al. Natural stranding of Atlantic sturgeon (Acipenser oxyrinchus Mitchill, 1815) in Scot's Bay, Bay of Fundy, Nova Scotia, from populations of concern in the United States and Canada. J Appl Ichthyol. 2017;33(3):317-22.

60. Rannala B, Mountain JL. Detecting immigration by using multilocus genotypes. Proc Natl Acad Sci. 1997;94(17):9197-201.

61. Wirgin I, Maceda L, Grunwald C, King TL. Population origin of Atlantic sturgeon (Acipenser oxyrinchus oxyrinchus) by-catch in U.S. Atlantic coast fisheries. J Fish Biol. 2015;86(4):1251-70.

62. Holbrook C, Hayden T, Pye J, Nunes A. Glatos: A package for the Great Lakes acoustic telemetry observation system. https://gitlab.oceantrack.org/Great Lakes/glatos.2018.

63. R Core Team. R: a language and environment for statistical computing. Vienna: R Foundation for Statistical Computing; 2018. http://www.r-proje ct.org/.

64. Farine DR. Asnipe: animal social network inference and permutations for ecologists; 2018. https://cran.r-project.org/web/packages/asnipe/asnip e.pdf.

65. Whitehead $H$, James R. Generalized affiliation indices extract affiliations from social network data. Methods Ecol Evol. 2015;6(7):836-44.

66. Guttridge TL, Gruber SH, Krause J, Sims DW. Novel acoustic technology for studying free-ranging shark social behavior by recording individuals' interactions. PLoS ONE. 2010;5(2):e9324.

67. Mourier J, Lédée E, Guttridge T, Jacoby D. Network analysis and theory in shark ecology — methods and applications. In: Shark research: emerging technologies and applications for the field and laboratory. Taylor \& Francis/ CRC Press; (CRC Marine Biology Series).

68. Ginsberg JR, Young TP. Measuring association between individuals or groups in behavioral studies. Anim Behav. 1992:44:377-9.

69. Whitehead $\mathrm{H}$. Precision and power in the analysis of social structure using associations. Anim Behav. 2008;75(3):1093-9.

70. Genoves RC, Fruet PF, Di Tullio JC, Möller LM, Secchi ER. Spatiotemporal use predicts social partitioning of bottlenose dolphins with strong home range overlap. Ecol Evol. 2018;ece3.4681.

71. Dekker D, Krackhardt D, Snijders TAB. Sensitivity of MRQAP tests to collinearity and autocorrelation conditions. Psychometrika. 2007;72(4):563-81.

72. Campbell LAD, Tkaczynski PJ, Lehmann J, Mouna M, Majolo B. Social thermoregulation as a potential mechanism linking sociality and fitness: Barbary macaques with more social partners form larger huddles. Sci Rep. 2018;8(1):6074

\section{Publisher's Note}

Springer Nature remains neutral with regard to jurisdictional claims in published maps and institutional affiliations. 